Vol. 4, No. 1, 2019

\title{
INVESTIGATION OF MIGRATION OF HEAVY METALS IN THE SOIL ENVIRONMENT ON THE EXAMPLE OF COPPER SULFATE
}

\author{
Oksana Lyuta, Vira Sabadash, Mariya Beymuk, Jaroslav Gumnitsky \\ Lviv Polytechnic National University, \\ 12, S. Bandera Str., Lviv, 79013,Ukraine \\ oksana.lyuta@gmail.com
}

https://doi.org/10.23939/ep2019.01.001.001

Received: 13.01.2019

(C) Lyuta O., Sabadash V., Beymuk M., Gumnitsky J., 2019

\begin{abstract}
The problem of permanent and prolonged pollution of soils by various kinds of pollutants, in particular heavy metals, was analyzed. Experimental investigations of penetration of copper sulfate into a vertical soil profile have been carried out. The adsorption capacity of the sandy environment of copper sulfate was experimentally determined.
\end{abstract}

Key words: pollution, soil, heavy metals, adsorption, penetration, migration.

\section{Introduction}

Constant getting of various kinds of substances into the environment leads to a long and continuous accumulation of pollutants. Mainly this problem concerns the soil environment due to the fact that it is very difficult to remove or neutralize the pollutants that enter the soil. In addition, there is a problem not only of the penetration of pollutants into a vertical soil profile, but also the accumulation of harmful substances in the soil layers, which leads to the transfer of pollutants to agricultural crops. Due to the fact that the soil selfpurification practically does not happen or occurs very slowly, all the pollutants that get on the surface of the soil gradually accumulate in it and lead to a change in the quality of the soil. Nowadays the main pollutants that affect fertility and quality of the soil are mineral fertilizers (in excessive amounts), pesticides and agrochemicals, heavy metals, petroleum products, etc. [1-3]. The penetration of any of these substances in one way or another leads to the soil contamination and, consequently, to the loss of its properties.

Heavy metals are among the main pollutants that are widespread throughout the territory of Ukraine. As for hazardous effect they concede only to pesticides that are widely used in agriculture as well as mineral fertilizers. The most common is the soil contamination with lead, zinc, cadmium, mercury and copper. The main sources of their income are industrial enterprises and agriculture. Thus, the introduction of, for example, mineral fertilizers is accompanied not only by the penetration of fertilizer residues into the soil profile, but also by the accumulation of heavy metals. Heavy metals are mostly found in phosphorus mineral fertilizers, less in nitrogen and potassium. The use of pesticides and agrochemicals (for example, copper preparations for vineyards treatment) is also accompanied by heavy metals and harmful chemicals getting into the environment that can penetrate into crops. In addition, heavy metals may get into the environment during the irrigation of crops if low quality water is used [4].

Like other substances, heavy metals have the ability to be adsorbed by soil and penetrate into deep soil horizons. Different factors influence the process of their distribution, in particular: granulometric composition, organic matter content, soil adsorption capacity, its type, etc.

The adsorption capacity is one of the most important properties that characterize the soil, because this ability both influences the processes of soil formation and determines its fertility by accumulation and retention in the pores the nutrients and essential substances needed for the proper development of plants. This property also plays a crucial role in the processes of transfer, accumulation and adsorption of pollutants by a soiladsorbing complex.

According to the literature sources, nowadays the main attention in the study of the processes of penetration of pollutants into the vertical soil profile is paid to the migration of mineral fertilizers and pesticides 
[4-7]. However, due to the current state of soils and the extent of pollution by heavy metals, insufficient attention was paid to the study of the process of penetration of heavy metals and their adsorption by the soil-adsorbing complex, taking into account that heavy metals have the ability to accumulate in the soil as they are adsorbed by the soil environment. That is why the study of these parameters is an urgent and topical task.

\section{Experimental part}

Copper is one of the most common heavy metals that are released into the environment. In addition to the fact that copper compounds enter the environment with emissions from industrial plants, they can still be contained in phosphorus fertilizers, pesticides, etc. Like the majority of heavy metals, copper compounds can distribute in the soil in three ways: adsorption by a soiladsorbing complex, migration in a vertical soil profile, diffusion and natural convection, and, in the presence of vegetation, penetration into the plants.

Investigations of the first two processes were carried out on the example of copper sulfate.

\subsection{Investigation of vertical migration of copper sulfate}

Investigation of the penetration of copper sulfate into a vertical soil profile was conducted in sandy soils. A vertical tank with transparent walls, filled with sandy soil, was used. Through transparent walls it was possible to observe the movement of the concentration front of copper sulfate, which is blue-green in the aquatic environment. At the beginning of the experiment, the layer of the sandy soil was filled with distilled water. The height of the experimental layer was $20 \mathrm{~cm}$.

To the surface layer of the investigated granular medium, a solution of $\mathrm{CuSO}_{4} \cdot 5 \mathrm{H}_{2} \mathrm{O}$ was introduced with an initial concentration $\mathrm{Cp}=19.4 \mathrm{~g} / \mathrm{dm}^{3}$ in a volume of $100 \mathrm{ml}$. Sampling was carried out at a depth of $0,5,10$, 15 and $20 \mathrm{~cm}$. For the analysis, samples were taken in 1, 2, 3, 4 and 5 hours in an amount of $2 \mathrm{ml}$.

The analysis of $\mathrm{Cu}^{2+}$ ions in the samples was carried out using a titrometric method according to the method described in [8].

The results of the experimental studies are presented in Fig. 1, 2.

\subsection{Investigation of the adsorption capacity of the soil}

To determine the adsorption capacity of copper ions, the investigation of $\mathrm{Cu}^{2+}$ ion adsorption by soil was conducted.

In order to do this, measuring volumes were filled with weighed mass $(10 \mathrm{~g})$ of sand which was dried to a constant mass and $100 \mathrm{ml}$ of copper sulfate solution with the known concentrations. After this, the solutions were thoroughly mixed and left for 2 days before the equilibrium condition was established.

Determination of the concentration of copper ions in the solution after the experiment was carried out by a titrometric method [8]. The mass of adsorbed copper was determined by the difference of the concentrations of the initial and final solutions. The concentration of copper ions was calculated according to the dependence:

$$
C=\frac{V_{\tau} * N * M_{C u^{2+}}}{V_{s}},
$$

where $V_{\tau}$ is the volume of sodium thiosulfate solution used for titration; $\mathrm{N}$ is the concentration of sodium thiosulfate solution, $\mathrm{mol} / \mathrm{cm}^{3} ; M_{\mathrm{Cu}^{2+}}=63.5 \mathrm{~g} / \mathrm{mol}$ is the molecular weight of copper ions; $V_{s}$ is the volume of solution taken for the analysis, $\mathrm{ml}$.

The results of the experimental studies are presented in Fig. 3.

\section{Results of investigation}

The copper ions entering the soil as a result of human activity are partially adsorbed by the adsorbent soil complex, while the rest penetrate into the vertical soil profile by molecular diffusion in the absence of plants, or are partially accumulated in plants.

According to the experimental studies, copper ions penetrate through the sandy environment rather quickly. So during the experiment, after 4 hours, the copper ions were recorded at a depth of $20 \mathrm{~cm}$. Taking into account that migration was not carried out below this level, further accumulation of copper ions occurred at this depth.

The results of the experimental studies are presented in Fig. 1, 2.

As it is seen from the presented graphic dependences, copper ions entering the soil environment, have the ability to easily migrate in a vertical soil profile, which creates a problem of the risk of contamination of deep layers of soil with heavy metals.

Fig. 1, e represents the concentration at a depth of $20 \mathrm{~cm}$. An increase in the concentration of $\mathrm{Cu}^{2+}$ ions at this depth means that no further migration occurs, and the mass of penetrating copper ions accumulates with time and is not taken away from the last layer.

Consequently, the concentration on the surface of the soil decreases, which reduces the flow of the substance from the surface, but copper ions accumulate in the deep layers, which results in an increase in concentration at a depth of 15 and $20 \mathrm{~cm}$.

Fig. 2 presents the changes of concentration at a particular depth, representing a general picture of copper ions migration. 


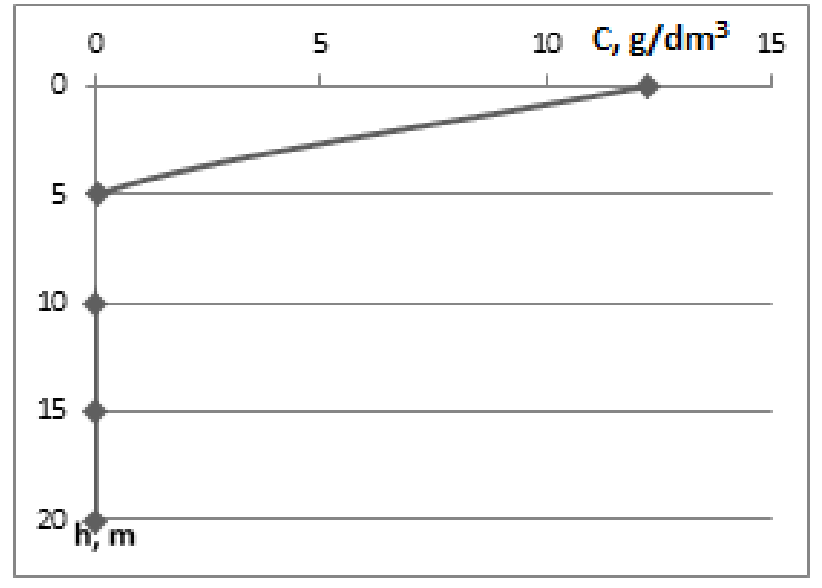

a

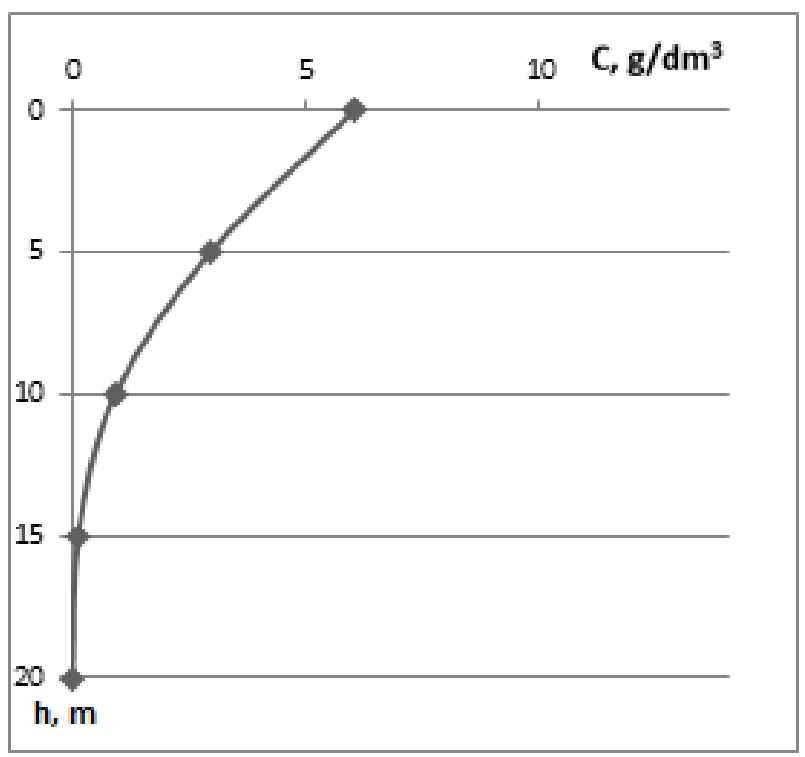

c

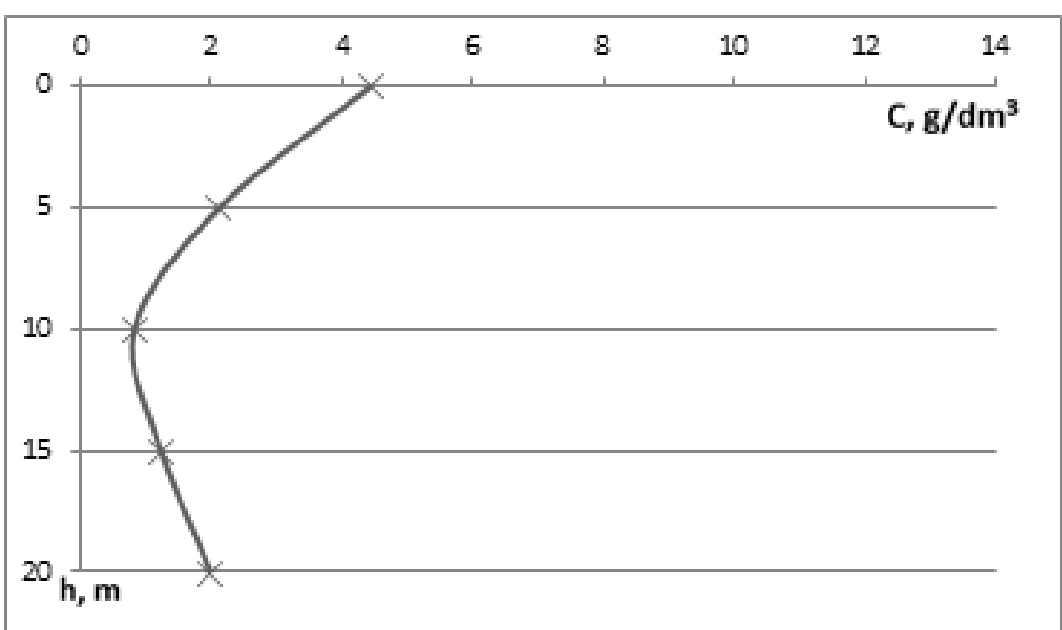

$\mathrm{e}$

Fig. 1. Change of the concentration of copper sulfate at the depth of the sand medium $h$ with time: $\mathrm{a}-1$ hour; $\mathrm{b}-2$ hours; $\mathrm{c}-3$ hours; $\mathrm{d}-4$ hours; $\mathrm{e}-5$ hours

b

d
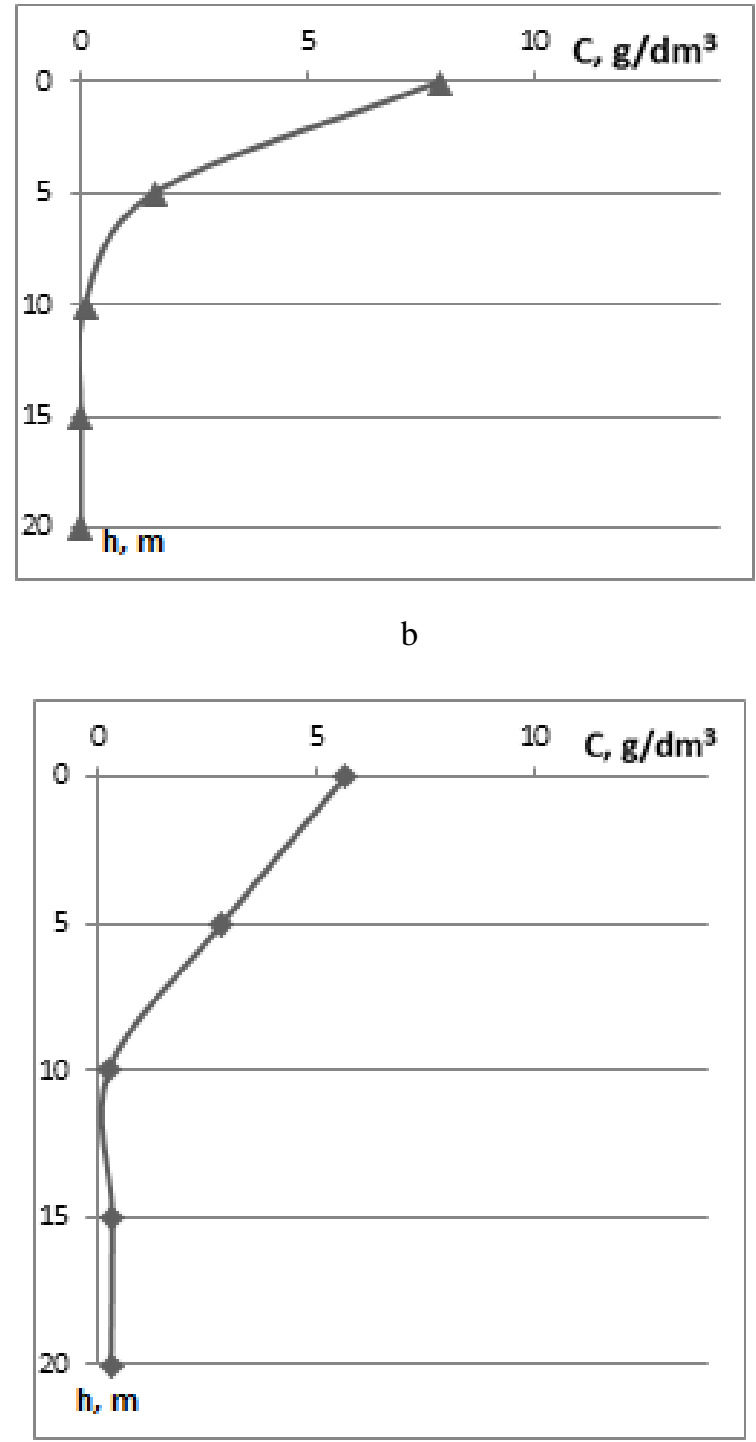


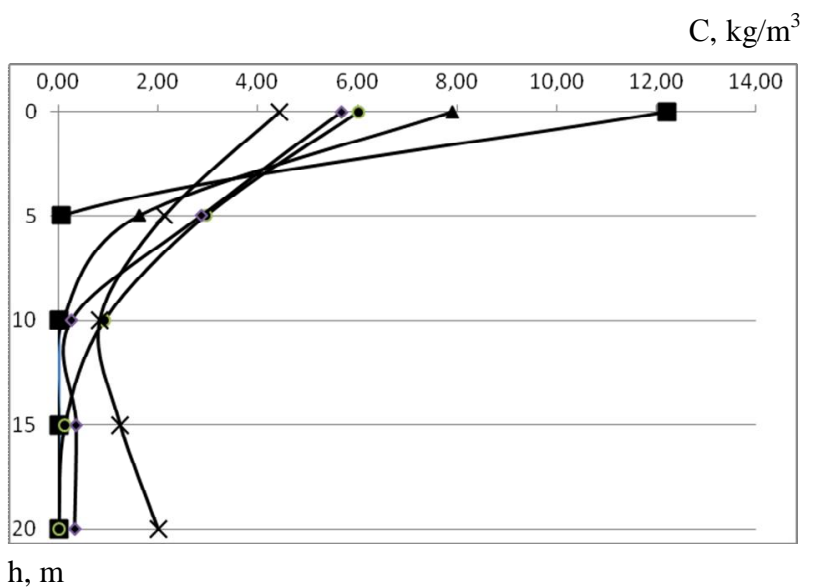

Fig. 2. Migration of copper sulfate in a vertical profile with time:

- 1 hour, $\Delta-2$ hours, $\bullet-3$ hours, $\downarrow-4$ hours, $\times-5$ hours.

Over time, copper ions penetrate deep into the soil, as evidenced by the results of the experimental studies. At a depth of $5 \mathrm{~cm}$, copper ions migrated in 1 hour from the beginning of the experiment, and then there was a slow accumulation of copper at a depth from 10 to $20 \mathrm{~cm}$, which explains the curvature of the curves on the graphic dependences.

Taking into account the fact that over time the concentration on the soil surface decreases, since more and ions of copper penetrate deep into the soil, the changes in the surface concentration value are shown in Fig. 3.

\section{C, $\mathrm{kg} / \mathrm{m}^{3}$}

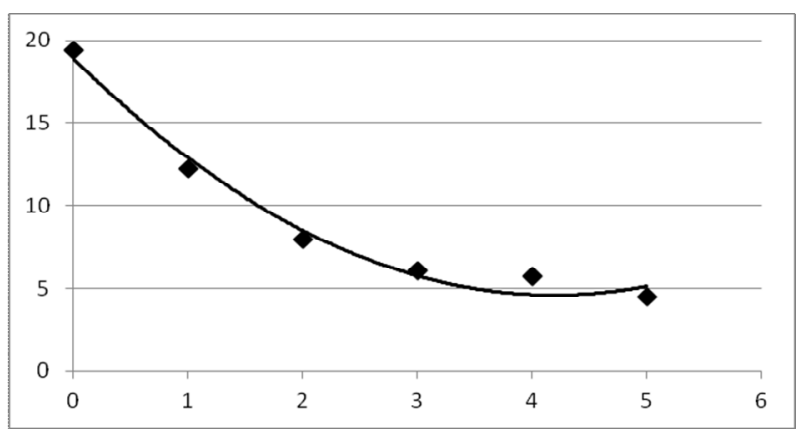

$\tau$, hour

Fig. 3. Changes in the surface concentration of copper ions depending on time

Fig. 3 presents changes in the surface concentration of copper ions. As can be seen from this dependence the concentration on the surface decreases with time, which corresponds to the conditions for the pollutant spill on the surface. This change can be approximated by a polynomial:

$$
\mathrm{C}_{\mathrm{p}}=0,8141 \cdot \tau^{2}-6,8205 \cdot \tau+18,87
$$

with determination coefficient $\mathrm{R}^{2}=0,9831$, which means a satisfactory description of this process.
At the same time, the part of the introduced copper is adsorbed by the soil environment, which leads to its accumulation in the arable layer of the soil.

The results of the experimental studies are presented in Fig. 4.

a, $\mathrm{g}\left(\mathrm{Cu}^{2+}\right) / \mathrm{g}(\mathrm{ads})$

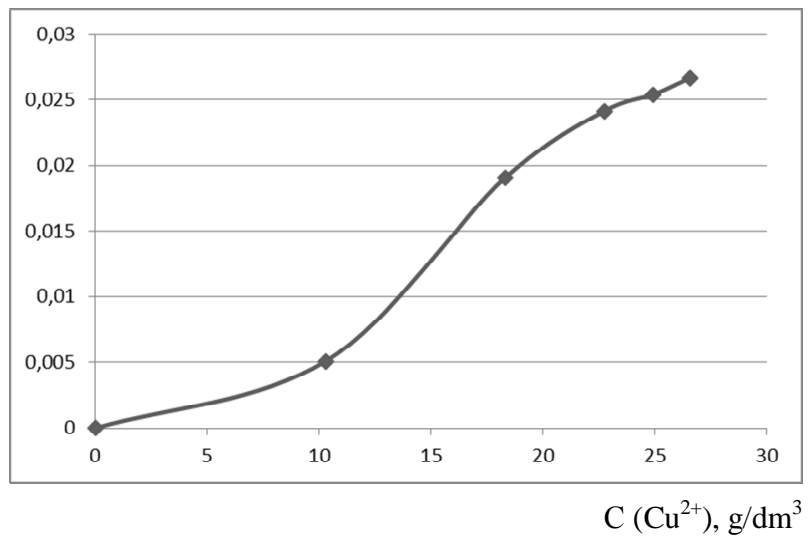

Fig. 4. Determination of the adsorption capacity of sandy soil by copper ions

In the area of low concentrations there is a lower adsorption capability of the soil. In this case, the influence of the adsorption capability of the medium has a less effect on the penetration of copper ions in the soil and takes place in a smaller amount. The increase in the concentration of the substance in the solution leads to the increase in the adsorption capacity of the soil environment.

Taking into account that the influence of adsorption properties is greater at high concentrations of a substance, then the higher the concentration of copper ions, the more they will be kept in the soil pores, and the greater contamination will be. This can lead to excessive accumulation of heavy metals in the arable soil layer and increase in their amount in the plants that will grow on this type of soil. However, on the other hand, such property of the soil makes it possible to reduce the penetration of heavy metals into the vertical soil profile and prevent their accumulation in deep layers.

\section{Conclusions}

Considering that the problem of environmental pollution, and in particular the soil, is increasing every year, there is a need for research and reduction of emissions which are not only hazardous but also accumulate in the arable layer of the soil and migrate into its deep layers. Such hazardous emissions include heavy metals that have the ability 
to accumulate and be kept in the soil pores, which leads to a decrease in the quality and fertility of the soil, as well as the penetration of their ions into plants.

The conducted experimental studies have shown that the adsorption properties of the soil have a significant influence on penetration and distribution of heavy metals into the vertical soil profile. This effect is especially significant at high concentrations of the substance, which creates favorable conditions for reducing the penetration of heavy metals into the deep horizons, but contributes to the contamination and accumulation of heavy metals in the arable layer. The obtained results of the experimental studies allow to estimate and predict possible soil contamination in the areas where there is a constant introduction of mineral fertilizers with high content of heavy metals, in particular phosphorous, or pesticides containing copper ions.

\section{References}

[1] Bakka M. T., Strel'chenko V. P.: Osnovy vedennya sil's'koho hospodarstva ta okhorona zemel'. Zhytomyr, 2000.

[2] D. Mel'nychuk, M. Mel'nykov, Dzh. Khofman, M. Horodniy ta in.: Yakist' hruntiv ta stratehiyi udobrennya. Aristey, Kyiv, 2006.

[3] Panas R. M.: Gruntoznavstvo. Novyy svit, Lviv 2006.

[4] Kazimierz Rup: Procesy przenoszenia zanieczyszczeń w środowisku naturalnym. Wydawnictwa Naukowo-Techniczne, Warszawa 2006.

[5] Humnyts'kyy Ya., Lyuta O., Sabadash V.: Énerhotekhnolohyy y Resursosberezhenye, 2009, 1, 62.

[6] Zaradny H. Prace Instytutu Budownictwa Wodnego PAN, 1990, 23, 367.

[7] Kladivko E. J., Van Scoyoc G. E., Monke E. J. et al.: J. Environmental Quality, 1991, 20/1, 264.

[8] Sabadash V. Kinetic regularities of copperions adsorptionby naturalzeolite / V. Sabadash, O. Mylanyk, O. Matsuska, J. Gumnytsky // Chemistry and Chemical Technology. 2017. - Vol. 11, No. 4, pp. 459-462. 